\title{
Pathways to a More Peaceful and Sustainable World: The Transformative Power of Children in Families
}

Pia R. Britto ${ }^{1}$, Suna Hanöz-Penney ${ }^{2,3}$, Liliana Angelica Ponguta ${ }^{4}$, Diane Sunar ${ }^{5}$, Ghassan Issa ${ }^{6}$, Sascha D. Hein 7 , Maria Conceição do Rosário ${ }^{4,8}$, Maha A. Almuneef ${ }^{9}$, Irem Korucu 4 , Yaya Togo ${ }^{10,11}$, Jamshed Kurbonov ${ }^{12}$, Nurlan Choibekov ${ }^{13}$, Hien Thi Thu Phan ${ }^{14}$,

N. Shemrah Fallon ${ }^{4}$, Bekir B. Artukoğlu ${ }^{4}$, Franz J. Hartl ${ }^{15}$, Rima Salah ${ }^{4}$, Siobhán Fitzpatrick ${ }^{16}$, Paul Connolly ${ }^{17}$, Laura Dunne ${ }^{18}$, Sarah Miller ${ }^{18}$, Kyle Pruett ${ }^{4}$, and James F. Leckman ${ }^{4}$

${ }^{1}$ Early Childhood Development Program, UNICEF, New York, NY, USA; ${ }^{2}$ Mother Child Education Foundation (AÇEV), Istanbul, Turkey; ${ }^{3} \mathrm{John}$ F. Kennedy School of Government, Harvard University, Cambridge, MA, USA; ${ }^{4}$ Child Study Center, School of Medicine, Yale University, New Haven, CT, USA; ${ }^{5}$ Istanbul Bilgi University, Istanbul, Turkey; ${ }^{6}$ Arab Resource Collective, Beirut, Lebanon; ${ }^{7}$ Freie Universität Berlin, Germany; ${ }^{8}$ Child and Adolescent Psychiatry Unit, Department of Psychiatry, Federal University of São Paulo, São Paulo, Brazil; ${ }^{9}$ King Saud ben Abdulaziz University for Health Sciences, Riyadh, Kingdom of Saudi Arabia; ${ }^{10}$ University of Sciences, Techniques and Technologies, Bamako, Mali; ${ }^{11}$ National Institute of Public Health of Mali; ${ }^{12}$ UNICEF Tajikistan, Dushanbe, Tajikistan; ${ }^{13}$ International University of Central Asia, Tokmok, Kyrgyz Republic; ${ }^{14} \mathrm{Ho}$ Chi Minh City University of Education, Ho Chi Minh City, Vietnam; ${ }^{15}$ Webmaster, Yale University, New Haven, CT, USA; ${ }^{16}$ The Early Years the Organization for Young Children Belfast, Northern Ireland, UK; ${ }^{17}$ Department of Educational Research, Lancaster University, Lancaster, UK; ${ }^{18}$ School of Social Sciences, Education and Social Work, Queen's University, Belfast, Northern Ireland, UK

Short title: Pathways to a More Peaceful and Sustainable World 
Address for Correspondence: James F. Leckman, Yale Child Study Center, New Haven, CT 06517; E-mail: james.leckman@yale.edu

\section{Conflict of Interest: None}

Acknowledgments. We gratefully acknowledge the contributions of the practitioners, families, and researchers who participated in each of the ECD-parenting programs mentioned in this article. We are also thankful for the generous support of many organizations and donors including: the Early Childhood Peace Consortium (ECPC), UNICEF, Anne Çocuk Eğitim Vakfi (AÇEV, the Mother-Child Education Foundation), the UBS Optimus Foundation, the Open Road Alliance, the Jacobs Foundation, the Melinda and Bill Gates Foundation, the National Family Safety Program in the Kingdom of Saudi Arabia, and the Arab Resource Collective. We are especially grateful to Ayşen Özyeğin, Ayla Göksel, and M. Yanki Yazgan who played a key role in the formation of the ECPC through their leadership of AÇEV. Likewise, the Early Years Organization and the LINKS initiative based at Queen's University Belfast (QUB) and funded by the National Institute for Health Research in the United Kingdom have provided key support for the ECD programs that are being piloted around the global. We also need to acknowledge the support by other universities in addition to QUB. They include Istanbul Bilgi University, the Freie Universität of Berlin, the Federal University of São Paulo, King Saud ben Abdulaziz University for Health Sciences in the Kingdom of Saudi Arabia, The Faculty of Medicine's Department of Public Health in the University of Sciences, Techniques and Technologies of Bamako in Mali, the International University of Central Asia, Ho Chi Minh City University of Education in Vietnam, Harvard University, as well as Yale University. 
Be totally committed to the optimal development of each child.

Good parenting benefits the community, as well as kids.

It is the environment that determines a considerable part of the growth and development of children.

I believe officials have listened to me over the years because they see me as a scholar, not as an advocate who has some other agenda. My only agenda, the one that has guided me throughout my career, is to serve the best interests of children and families.

Edward Zigler (1930-2019)

\begin{abstract}
This article provides an overview of selected ongoing international efforts that have been inspired by Edward Zigler's vision to improve programs and policies for young children and families in the United States. The efforts presented are in close alignment with three strategies articulated by Edward Zigler: (1) conduct research that will inform policy advocacy; (2) design, implement, and revise quality early childhood development (ECD) programs; and (3) invest in building the next generation of scholars and advocates in child development. The intergenerational legacy left by Edward Zigler has had an impact on young children not only in the United States, but also across the globe. More needs to be done. We need to work together with a full commitment to ensure the optimal development of each child.
\end{abstract}


Keywords: Early childhood development; parenting programs; peacebuilding; 2030 Sustainable Development Goals; advocacy and social policy

The case for early childhood development (ECD) has been made. As a field, scholars and practitioners in psychology, psychiatry, neurology, pediatrics, public health, economics, education and related disciplines are becoming increasingly aware of the importance of ECD in setting the stage for the emergence of neurodevelopmental and neuropsychiatric disorders later in life (Cicchetti \& Sroufe, 2000). Beyond psychopathology, it is also clear that events early in a child's life can directly impact their physical health, learning and well-being and the degree to which a child is able to reach their full developmental and economic potential, which rests in large part on the positive interaction between genes and the environment or "nature via nurture (Britto et al., 2017; Daelmans et al., 2017). This science has conveyed a message of hope and change, that by altering contexts for young children, their life trajectory can be positively influenced. As a world community, policy makers, civil society, media and advocates are also becoming increasingly aware that the early years of life can set the foundation not only for individual children but also for the societies in which they live (Clark et al., 2020). This recognition could not be timelier as the world grapples to formulate the "reset" button, following the COVID-19 pandemic, by prioritizing actions that will serve to build back a brighter future. Elevating the agenda for young children and parenting are key investments of the formula.

\section{Strategy 1: Research for Policy Advocacy}

Beginning in 1959 and well into the $21^{\text {st }}$ century, Edward Zigler's research focused on improving services for the most disadvantaged children, particularly those living in poverty and with disabilities. The aim of his research was to inform and improve social policies ${ }^{1}$. 
Zigler's scholarship aim to influence social policy has seen continuation in the global arena with The Lancet Early Childhood Development Series that was published in January 2017. This issue focused on the latest scientific evidence for ECD and parenting interventions. This series reported that, based on proxy measures of stunting and poverty, approximately 250 million, or $43 \%$ of children under the age of 5 years of age are at risk of not achieving their developmental potential (Black et al., 2017). These articles are particularly timely and significant because they were released immediately after the world community universally endorsed ECD as a transformative element in the 2030 Sustainable Development Goals (SDGs).

The SDGs are a collection of 17 global goals designed to be a "blueprint to achieve a better and more sustainable future for all" (United Nations, 2020). The SDGs were approved in 2015 by the United Nations (UN) General Assembly. To achieve the SDGs by 2030, it is clear that national policies and programs for all children need to be strengthened. Indeed, the recent WHOUNICEF-Lancet Commission report that was prepared by the World Health Organization and UNICEF entitled, "A future for the world's children?" makes a compelling case that the needs of children should be at the center of SDG policies (Clark et al., 2020). The Lancet Commission's report presents a "flourishing index" (FI; range - lowest 0.0 to highest 1.0 ) for each country which reflects a number of key indicators of child wellbeing that are each closely linked to the SDGs (Clark et al., 2020).

1. In 2008, T. Barry Brazelton, on his $90^{\text {th }}$ birthday, asked Kyle Pruett to drive him from Boston to Edward Zigler's home in Connecticut. Kyle recalls a frank and open discussion over lunch during which Zigler said, “Don't tell people what they should feel - they don't 
like it, and it doesn't help. Show them what they can change and tell them what the data shows regarding why they should change."

The Lancet ECD series (2017) also provides evidence-based recommendations regarding how best to strengthen national policies and programs as well as a framework to understand the holistic needs of the developing child. Our genetic blueprint provides only the broad strokes of the development of our bodies and brains; it is the quality and timing of early environments that shape a child's future potential during critical periods of development, from pre-conception onwards. Indeed, how a child is parented provides a legacy that transcends their genes (epigenetics) and can directly affect the development of the child's brain, their cognitive and socioemotional skills, as well as their mental and physical health (Black et al., 2017). The Lancet series summarizes this holistic framework as "nurturing care" and identifies five inter-related components that need to be addressed for children to reach their full developmental potential: 1) security and safety, 2) adequate nutrition, 3) access to health services, 4) responsive caregiving, and 5) early learning opportunities. The importance of "nurturing care" is manifested through behaviors, attitudes, and knowledge about caregiving (e.g., health, hygiene care and feeding); stimulation (e.g., talking, singing and playing); responsiveness (e.g., early bonding, secure attachment, trust and sensitive communication); and safety (e.g., routines, protection from violence, abuse, neglect, harm and environmental pollution) (Britto et al., 2017).

Many children in our world do not receive adequate nurturing care (Clark et al., 2020). They lack adequate nutrition and positive and responsive parenting practices. For many children, even their homes do not provide a safe haven. Every year, hundreds of millions of children are exposed to and are victims of domestic violence and harsh parenting, often from an early age (Hillis, Mercy, \& Saul, 2017). It is also estimated that globally one in ten children are sexually 
abused before the age of 18 years (https://www.childhood-usa.org/). Other challenges include the presence of parental psychopathology and the use of addictive substances by parents. As a result, hundreds of millions of children are growing up in the context of "toxic stress" and as a result may fail to reach their full developmental potential (Shonkoff et al., 2012). This reality clearly points to the urgent need for global action.

In addition to exposure to violence, abuse, neglect and/or exploitation, toxic stress encompasses other unfortunate circumstances in which children lack adequate nutrition and positive and responsive parenting practices. Thus, many of these children growing up in toxic stress will fail to reach their full developmental potential (Shonkoff \& Garner, 2012). This reality clearly points to the urgent need for global action.

The Lancet series, in keeping with the applied research of Edward Zigler, summarizes evidence-based interventions that have shown significant benefits throughout the life course (Britto et al., 2017). It highlights both the affordability of early childhood interventions as well as the high cost of inaction. The four actions recommended by the series echo Edward Zigler's determined efforts to serve the best interests of children and families in the United States through the provision of universal high quality ECD programs (Zigler \& Styfco, 2002).

\section{Action item 1: Expand political will and funding through advocacy for the young child}

related SDGs. Under the SDG umbrella, investing in ECD is not only an aim in itself, but it is also a requisite for achieving several other SDGs (e.g., SDGs 1-5, 10, 16, and 17). For example, SDG 4.2 calls for universal access to quality ECD, care, and preprimary education, and provides unprecedented opportunity to scale up ECD services. At a time when deceleration of results for infants and young children is forecast, due to the disruption of basic services, the imperative to prioritize the young child targets of the SDGs is even greater. 
Action item 2: Create a policy environment that supports nurturing care of young

children. Efforts to improve childhood development and ensure nurturing care require the support of government officials and policymakers who need to identify gaps and priority areas for intervention and develop sustainable and cost-effective action plans. Five transformative policies for which there is robust global data include: 1) paid parental leave for new mothers and fathers; 2) breastfeeding breaks at work; 3) paid leave for parents to care for sick children; 4) income support through a minimum wage; and 5) tuition-free preprimary education.

\section{Action item 3: Build capacity to promote ECD through multi-sectoral coordination. In} each setting, interventions are highly dependent on the availability of skilled human resources to broaden their scope and provide equitable access and can be implemented by government and non-government agencies. The integration of ECD interventions into existing service delivery platforms such as health and nutrition services, starting with family planning and routine antenatal care and continuing through early childhood, is the best way to reach large numbers of families and children. Multiple lessons can be learned from the U.S. Administration for Young Children and Families on multi-sectoral coordination to improve outcomes for children living in low income families and communities (https://www.acf.hhs.gov/). The enabling environment created through these policies serves to support parents and elevate parenting as an accelerator to achieve optimal developmental outcomes for young children.

Action item 4: Ensure accountability for early child development services, increase research, and foster global and regional leadership and action. Ensuring the inclusion of a core set of ECD indicators is of paramount importance. Research that links detailed longitudinal data on policies and programs with outcomes, allowing causal modelling, is essential to ensure continuing progress of the field. The newly released "Early Childhood Development Index" 
ECDI-2030 (https://indicators.report/indicators/i-32/), has been endorsed by the UN Statistical commission as the tool to measure SDG 4.2.1 (referenced above) and is the first ever populationbased tool for measuring young children's development.

The Early Childhood Development Action Network (ECDAN). ECDAN is a nascent global alliance of over one hundred organizations and networks, with thousands of members committed to improving the lives of young children from conception to five years of age. Its inception is closely aligned with Action items presented in the 2017 Lancet series. As expressed by the G20 (2018 leaders' communique), ECDAN serves as a platform for knowledge exchange across countries and communities, including technical resources, policy trends and advocacy materials, and provides mechanisms for collaborative action at local, national, regional, and global levels. In addition, ECDAN advocates for equitable resources and services for young children and their families by launching a global movement to spur investment and to help countries achieve the SDGs by meeting the needs of children.

Next Steps. While there is a significant awareness of the importance of nurturing care to ensure children's well-being and optimal development, much of what we know remains at the level of a framework. Evidence is required on how best to implement and sustain programs of proven value, within existing services and delivery systems (Britto, Singh, Dua, Kaur, \& Yousafzai, 2018). This gap in our knowledge is being actively addressed by a working group of more than 30 researchers, practitioners, non-governmental organizations (NGOs) and advocates headed by experts based at UNICEF, and by the intramural program at the National Institute of Child Health and Human Development (NICHD), funded by the LEGO Foundation. This effort has sought to identify “The Knowns, Unknowns, and What Should be Known” regarding the next generation of ECD and parenting interventions. Three technical consultations were held in 
2019, with the aim of developing a research agenda to inform the design, implementation, refinement, and dissemination of the next generation of ECD parenting programs that will help achieve the 2030 SDGs.

\section{Strategy 2: Design and Implementation of Quality Programs - The Promise of ECD Programs}

as a Path to a More Peaceful World. While ECD programs in high income countries (HICs) can be dated back to the 1800s (Zigler \& Hall, 2000), it was only in the 1970s that they started to emerge in low- and middle-income countries (LMICs) (United Nations Educational, Scientific, and Cultural Organization [UNESCO], 2007) and only very recently have they begun to be implemented in most countries of the world (Britto \& Gilliam, 2008). This follows Edward Zigler's second strategy which was to design and implement quality programs for vulnerable young children and families in the United States. In the early 1970s, he and his team helped to initiate and refine the Head Start program as part of an antipoverty program that had begun in the 1960s, which aimed to build the developmental potential of young children (Greenberg, 2004; Zigler \& Anderson, 1979).

The evidence is clear, ECD programs are one of the most cost-effective strategies for poverty alleviation. Multidisciplinary research findings demonstrate that family and communitybased ECD services are cost-effective and have the potential to contribute to reducing the inequality that is so often present in LMICs as well as in marginalized communities within HICs, based on the benefits that accrue to individuals, communities, systems and societies in the long term (Heckman, Moon, Pinto, Savelyev, \& Yavitz, 2010; Heckman \& Raut, 2016).

In the $21^{\text {st }}$ century, as before, many children do not receive optimal care. This reality is compounded by the situations of inequality, war, conflict, pandemics, and migration to which many families are exposed. More children than ever before — at least 420 million globally_are 
now living in areas affected by conflict (Graham, Kirollos, Knag Fylkensnes, Salarkia, \& Wong, 2019). Sadly, it is estimated that 29 million babies were born into conflict affected areas in 2018 (UNICEF, 2019a). Worse yet, as estimated in a recent report by the UN, every five minutes, somewhere in the world, a child is killed by violence (UNICEF, 2019a).

One of the biggest issues facing ECD programs is understanding the evidence for the potential to build social cohesion within extended families and communities - as a pathway to peace from one generation to the next (Connolly, Hayden, \& Levin, 2007; Leckman, PanterBrick, \& Salah, 2014). To date, emerging science indicates that if societies invest in quality ECD services, this can truly be transformative (Britto et al., 2014).

The Early Childhood Peace Consortium (ECPC). The ECPC was founded in 2013 on the belief that the global community must address the root causes of violence and conflict, and that children and families can be agents of change for peace. The formation of the ECPC was inspired by: 1) the work of His Excellency, Ambassador Anwarul K. Chowdhury and the landmark resolution from the United Nations General Assembly, the "Declaration and Program of Action on a Culture of Peace" (UN Resolution A/RES/53/243, adopted in September 1999); 2) the findings of the Mother Child Education Foundation (Anne Çocuk Eğitim Vakfi [AÇEV], 2008) in Turkey (ACEV, 2012); and 3) the deliberations of 50 world experts from a broad range of disciplines at the $15^{\text {th }}$ Ernst Strüngmann Forum in October of 2013 in Frankfurt, Germany (Leckman et al., 2014). The Consortium's mission is to create an inclusive movement for peace, social cohesion, social justice, and the prevention of violence through using ECD strategies to enable the world community to advance peace, security and development. The Objectives of the ECPC are closely aligned with the goals of ECDAN and the 2030 SDGs. 
Objective 1. To link emerging knowledge from bio-behavioral and environmental sciences with existing evidence to increase investment, advocate for and create local and sustainable programs, as well as policies and systems for peacebuilding and reduction of violence through ECD programs.

Objective 2. To contribute to peacebuilding by focusing on ECD and engaging families, communities, civil society, governments and philanthropists through science, practice and policy development.

Objective 3. To advocate and disseminate information for academics, policy makers, networks, providers of family-relevant social services, parents, caregivers and children to build a global movement that values young children and families as agents for peace. This information is disseminated in print and digitally via the ECPC website (https://ecdpeace.org/).

\section{Peacebuilding ECD Programs across the Globe}

In this section we highlight programs internationally that seek to advance social cohesion and peacebuilding through ECD and parenting programs. We begin with the Mother Child Education Foundation (AÇEV) based in Turkey (https://www.acev.org/en/). We then turn to The Early Years Organization in Ireland (http://www.early-years.org/) and the LINKS Initiative that is being supported by the National Institute for Health Research (NIHR) Global Research Group on ECD for Peacebuilding based at Queen's University in Belfast. The LINKS Initiative is currently providing support for ECD programs that are being piloted in conflict affected regions of the world (https://www.qub.ac.uk/sites/links/).

AÇEV (Anne Çocuk Eğitim Vakfi) (authored by S. Hanöz-Penney and D. Sunar). AÇEV was founded in 1993 with the aim of providing early childhood education using the methods of the Turkish Early Enrichment Project (TEEP) (Kağıtçıbaşı, Sunar, Bekman, Baydar, \& 
Cemalcilar, 2009). TEEP consisted of an innovative, home-based program in which mothers were trained to provide cognitive enrichment to their preschool aged child, combined with a group-based mother support program. This two-pronged approach was later modified by AÇEV for community application and became known as the Mother-Child Education Program (MOCEP). The original TEEP research (Kağıtçıbaşı, Sunar, \& Bekman, 2001) drew its inspiration in part from pioneering programs such as Head Start, championed by Edward Zigler and his colleagues.

The current form of MOCEP is a group-based, 20 to 25-week ECD program designed for mothers of children 4 to 6 years of age who do not have access to formal preschool education. For the child, MOCEP seeks to improve a child's cognitive and socioemotional development and to support her or his readiness for school. For the mother, her participation in the support and discussion groups has the potential to improve her self-efficacy skills as well as ensure that the home environment is nurturing and healthy. For the family, the local community and society as a whole, ECD programs like MOCEP have the potential to foster social cohesion and peacebuilding.

Ongoing implementation research has made MOCEP more responsive to the needs of the participants. For example, when mothers expressed the need to enhance family cohesion and engage fathers, AÇEV developed a separate program for fathers. Similarly, MOCEP's content was expanded to include themes of social cohesion, child protection and violence prevention (Sunar et al., 2013). The original TEEP intervention was found to have favorable long-term effects, into the children's early adulthood. Unfortunately, a similar follow-up study of MOCEP's effects is not available; nevertheless, qualitative observations suggest long-term 
positive effects (Bekman \& Koçak, 2011). Despite this promise, challenges remain in implementing MOCEP and bringing it to scale in Turkey and beyond.

International Exemplars of AÇEV's MOCEP. International applications of MOCEP have been part of AÇEV's mission nearly from its earliest days. Initially, applications were carried out with Turkish migrant populations in European nations including Belgium, Germany and Switzerland. In addition to Turkish speaking families in Europe, MOCEP has now been translated and culturally adapted with partners across multiple countries. As of 2019, culturally adapted versions of MOCEP have been implemented in more than 14 countries. In these settings, MOCEP is carried out by local partners who are responsible for the translation and adaptation of MOCEP to the local language and culture. They also mobilize trainers, recruit participating families, and raise funds to implement MOCEP in close consultation with AÇEV. Indeed, after MOCEP was adapted and piloted in Lebanon, Brazil, and Saudi Arabia, randomized clinical trials (RCTs) have been or are currently being conducted (Ponguta et al., 2020; Ponguta et al., 2019a).

The Impact of MOCEP among Refugee and Other Marginalized Communities in Lebanon (authored by L.A. Ponguta, G. Issa, S.D. Hein, \& J.F. Leckman). The Arab Resource Collective (ARC) has been implementing a locally adapted version of MOCEP in Lebanon since 2009. In 2013, the UBS Optimus Foundation, The Open Road Alliance, AÇEV, and Yale University provided funding to support a pilot RCT to evaluate the impact of MOCEP on vulnerable populations in Beirut, Lebanon (ClinicalTrials.gov Identifier: NCT02402556). Participants were residents of three communities in Beirut: Bourj El Barajneh, Shatila, and Chiyah. Both Bourj El Barajneh and Shatila are areas of the city specifically designated for refugee families and have historically been home to members of the Palestinian refugee community. They include a large 
number of refugees from Syria including some whom are of Palestinian origin. Chiyah, by contrast, is a neighborhood in Beirut that is home to predominantly low-income Lebanese families. The directors of community service centers located within each community facilitated the recruitment process. The implementation of the pilot RCT at the three sites took place in 2015 and 2016. A total of 106 mother-child dyads were randomly assigned to either an intervention group $(n=53)$ or a wait-list control group $(n=53)$. After completing the program, assessors, who were blind to whether or not the mother had participated in MOCEP, determined that the mothers in the intervention group showed both a significant reduction in harsh parenting behaviors and in their level of perceived stress in their role as a parent (Ponguta et al., 2020; Ponguta et al., 2019a). However, the immediate impact on the children was limited, most likely because a majority of the children already had access to early childhood development and education programs at their local community service centers. To date, a lack of funding has precluded a longitudinal follow-up of these children to determine whether a positive impact of MOCEP would have become evident at a later stage of the children's development.

Qualitative data concerning the impact of MOCEP was also obtained from both mothers and fathers in focus group discussions (FGDs) and one-on-one interviews before and after the RCT (Hein et al., 2020; Ponguta et al., 2019a). Prior to the program being implemented, some mothers initially showed a degree of resistance based in part on the perception that parenting knowledge is innate. Many of the mothers reported that yelling, punishing, ignoring, and hitting were commonplace in their homes. During MOCEP, the mothers reported that they realized that they needed to change their behavior. One mother said, "Now I have changed the way I treat my kids, and the way I deal with our family's problems." Another said, "In my community, beating the child is the normal way to educate him. The program changed me radically. I learned how to 
deal with my son's and my daughter's conflicts without yelling and shouting." Mothers also frequently reported their joy in establishing an emotionally positive relationship with their child and how that positive change was empowering to them and to their children.

In addition to responses from the mothers, fathers also reported benefits to their marriage and to their family. For example, one father mentioned that his relationship with his wife "has become much better. Once she's calm, I become calm, and our lives are now much better than before." Several of the fathers mentioned the positive changes in their social interactions with other members of their community. For example, one husband described how his wife's behavior had changed, "She improved the way she interacts with me, her family and her friends, became more social."

To explore the impact of MOCEP on perceived social cohesion, the mothers were also asked to discuss their feelings about the social dynamics within their group. There was a sense that the groups provided direct support, a space for socialization, and that this in turn improved their self-confidence. In many instances, the mothers established groups in social networking and communication apps/programs (e.g., on WhatsApp) so that they could continue to connect with one another following the completion of the study.

Given the ongoing conflicts in the Middle East and the day-to-day challenges that families are facing in the region, Dr. Issa, who directs $\mathrm{ARC}$, and his team have now developed a more condensed parent training program, the 'Health, Early Learning and Protection Parenting Programme'. It is currently being scaled up following an evaluation of a recent pilot implementation in both Lebanon and Jordan (Lakkis et al., 2020).

Importantly, ARC also now hosts the Arab Network for Early Childhood Development (ANECD; https://anecd.mawared.org/en). ANECD is the Middle East regional hub for ECDAN 
and it seeks to ensure the development potential of all young children in all Arab countries through the production and dissemination of knowledge, sharing of best practices, and advocating for policies that support the care and development of young children. As with MOCEP, this new program actively brings together multiple partners including government officials, academics, and NGOs, as well as experts and practitioners from across the region. Unfortunately, the ongoing COVID-19 pandemic has created many challenges for the implementation of ECD programs in the region.

Mother Support Program (MSP) in Brazil (authored by M.C. do Rosário; https://www.facebook.com/programaprimeirainfancia). Brazil is among the countries with the highest income inequality indexes (Clark et al., 2020). Although Brazil has reduced the number of people living in extreme poverty, in 2012 , there were still 2.5 million people living $(\sim 1.3 \%)$ below the extreme poverty line. Rates of domestic violence in Brazil are also extremely high (Rodrigues et al., 2017). In June 2015, after participating in two symposia held in Istanbul that were organized by the AÇEV Foundation, Yale University and UNICEF, Professor Rosario was convinced that it was imperative to implement ECD parenting programs in Brazil to mitigate the deleterious effects of the direct and indirect violence on young children's socioemotional development. $^{2}$

2. Of note, while preparing this article, Professor do Rosário recalled being introduced to Edward Zigler while visiting him in his home in 2014. During her visit, Professor Zigler mentioned that one of his happiest moments in recent memory was when his surgeon at a local hospital thanked him for being the "father of Head Start". The doctor told him that 
he had participated in a Head Start program when he was a child and that the experience had completely changed his life's trajectory.

In 2016, an implementation of the Brazilian adaptation of AÇEV's MOCEP, named the Mother Support Program (MSP), was initiated in the city of Embu das Artes, located in the metropolitan area of São Paulo. Embu das Artes has high levels of urban violence, economic disadvantage, and substance use disorders. The city's Secretary of Education gave permission to the Brazilian team to contact the coordinators and teachers from the city public pre-schools who in turn gave them access to all mothers of 3 to 6-year-old children enrolled in the public preschools. Following a series of FGDs with mothers living in Embú das Artes, the Early Childhood Support Program (Programa de Atenção a Primeira Infância, PAPI) implemented the MSP. PAPI is an interdisciplinary team composed of psychiatrists, psychologists, pediatricians, nutritionists and speech therapists. This project is being funded by the Melinda and Bill Gates Foundation and the Brazilian National Council for Research.

The MSP is a 13-week group-based ECD parenting program designed for mothers of children 3-6 years of age. The sessions provide a setting in which mothers and caregivers can model pro-social behaviors and practice conflict resolution techniques with young children. It is an empowerment program that improves parenting and parent-child relationships by focusing on parental well-being, positive parenting skills and conflict resolution. The sessions, which are carefully designed to have a parent-friendly language, hold various activities that address: narratives and theoretical information about program topics; specific questions to evoke a mother's reflection on program topics and on her own early childhood experiences; role-play techniques; group discussions; and discussion of examples of events during mothers' interactions with their children and families during the course of the program. 
To date, 255 mothers of 3 to 6-year-old children have participated in 24 MSP groups. Initial qualitative analyses have revealed that before participating in the MSP, mothers reported that they often felt tired and overwhelmed with their workloads. They also felt that they had very little social support. They also felt impotent to make any changes in their family environments. They did not recognize the long-term negative impact of conflict and violence in their homes. They also frequently underestimated their children's abilities and expressed belief that they did not need to receive parent training. After participating in the MSP, the mothers reported in FGDs feeling "less anxious and tired" and "less lonely" because the group had become a source of support for them within their communities. They also stated that: 1) their interactions with their children were more sustained and pleasant; 2) they had learned strategies to manage undesirable behaviors of children without violence; and 3) that their homes had become more "peaceful". Many mothers were also surprised and delighted by their children's new abilities and progress in pre-school.

In addition, to the FGDs, quantitative analyses are currently underway to assess the impact of the MSP on the cognitive and social development of the children as well as the level of maternal stress. Similar to the RCT in Lebanon, the mothers are also being assessed with regard to harsh parenting behaviors and whether or not there have been changes in their interactions with the fathers of the children and other members of their community.

In 2019, the PAPI team was invited to implement the MSP for 266 families living in very vulnerable conditions in the City of Sobral, in the state of Ceará that lies in the northeast region of the country. The PAPI team is very excited about the implementation of the MSP in this new, culturally diverse city and are hopeful that the experience will provide more information on how 
to develop a scale-up plan for the MSP in Brazil. Unfortunately, the ongoing COVID-19 pandemic has placed the implementation of MSP in jeopardy.

MOCEP in Saudi Arabia (authored by M. A. Almuneef). The future of Saudi Arabia, as with other countries, is highly dependent on its youth. In Saudi Arabia, 48\% of the population is under 18 years of age and approximately $10 \%$ are younger than five years of age. In Saudi Arabia, shouting at and beating children are socially sanctioned forms of discipline in the home, and corporal punishment is a common form of discipline in schools (Al Eissa \& Almuneef, 2010). The Child Care Association (CCA) and the National Family Safety Program at the King Abdulaziz Medical City-Ministry of National Guard Health Affairs have been implementing MOCEP for more than a decade. The Saudi government in its 2030 Vision statement, stressed the importance of investing in national programs to support the optimal development of young children and to reduce domestic violence and child abuse (Alzahrani, Abaalkhail, \& Ramadan, 2016; Vision2030 [https://vision2030.gov.sa/en]).

Initially, MOCEP was implemented in Riyadh. By 2013, it had expanded to include all 13 regions of Saudi Arabia. To date, more than 12,000 mothers have participated in MOCEP. Despite this progress, many challenges remain including difficulty in reaching mothers in remote areas of the Kingdom and in very poor districts of cities. It has also been a challenge to monitor and maintain high quality implementation of the MOCEP program, which requires sustained effort from the CCA. Providing the necessary funding to train the trainers and provide them with sufficient financial support to deter them from moving on to other employment opportunities is another major challenge. At present, the Saudi Arabian adaptation of MOCEP is being evaluated by researchers from Saudi Arabia in collaboration with colleagues from the Freie Universität Berlin and Yale University. Approximately 200 mother-child dyads will be enrolled in the RCT 
with half in the intervention group and half in the wait-list control group. This rigorous evaluation is sought to ensure the continuing support for MOCEP across the Kingdom for years to come. Unfortunately, the ongoing COVID-19 pandemic has placed the implementation of MOCEP in the Kingdom in jeopardy.

The Early Years Organization (authored by S. Fitzpatrick). The Early Years, the Organization for Young Children (https://www.early-years.org/), formerly known as the Northern Ireland PreSchool Playgroup Association, was founded in 1965 with the aim of developing community-led preschool services. Three years later in 1968, Northern Ireland witnessed the beginning of a 30year conflict, which had a devastating impact on every community across Northern Ireland. This led the organization to refocus its commitment to supporting the development of preschool services where children and families from both the Protestant and Catholic communities could come together to build trusting and respectful relationships. During the worst years of the conflict, this effort grew and by the beginning of the 1990s, virtually every small community across Northern Ireland had initiated a community-managed preschool playgroup or parent and toddler group.

In 1994, after the paramilitary ceasefires, the European Union (EU), through the Special Support Programme for Peace and Reconciliation, recognized the importance of the organization as one of the key strategic partners in building and sustaining peace and reconciliation in Northern Ireland. From 1994-2020, the EU has invested significantly in supporting the early years sector across Northern Ireland and the Southern Border Counties in the Republic of Ireland. With financial support from the EU, the International Fund for Ireland, the Atlantic Philanthropies and the Department of Education in Northern Ireland and with research support from Queen's University Belfast, the Early Years Organization developed the Media Initiative 
for Children Respecting Difference Programme (MIFC) for preschool children, their parents, teachers and the wider community. The aim of the program is to build a culture of respect for those who are different in terms of race, religion, ethnicity and disability. The curriculum of the program intentionally supports young children to develop positive self-identities and respectful positive attitudes towards others who are "different". The curriculum is supported by a range of culturally and contextually appropriate resources that reflect the nature of division in Northern Ireland. Teachers and parents also receive in-depth experiential learning opportunities that help them reflect on their own attitudes and beliefs and supports them to develop positive inclusive strategies to work with young children. The preschool program is also supported by a multimedia strategy with six, one-minute cartoon animations being broadcast on national television for three weeks during the three terms of the school year.

Thus far, MIFC has been subjected to several qualitative and quantitative evaluations. In 2010, Queens University Belfast carried out an RCT in 76 preschool settings in Northern Ireland and the Republic of Ireland that found significant positive results in terms of children's social and emotional well-being and their willingness to include others who were different in their play (Connolly, Miller, \& Eakin, 2010). Since then, the program has been implemented at scale across Northern Ireland and is being used to support the new Shared Education Policy in Northern Ireland and the Republic of Ireland where children from different religious backgrounds are experiencing a minimum of 30 hours shared preschool educational activity each term. The program has also been adapted, implemented and evaluated in the Balkans, Kyrgyzstan and Tajikistan with plans for implementation in Colombia, Israel and Palestine. In Northern Ireland, MIFC has been further developed to cover the age range 2 to 11 years. A program for 2- and 3- 
year-old children is currently being piloted in a SureStart Developmental Programme, and it is currently being evaluated by Fielding University.

\section{LINKS (The NIHR Global Health Research Group on Early Childhood Development for}

Peacebuilding (authored by S. Miller, L. Dunne \& P. Connolly). Inspired by the work of The Early Years Organization and Queen's University Belfast in relation to the adoption of an evidence-based approach to the development of the MIFC, Queen's University Belfast has partnered with UNICEF, Yale, Harvard and New York University to lead a new global research network that is funded by the National Institute for Health Research (NIHR) in the United Kingdom. The LINKS initiative is an associated project of ECPC whose goal is to support the development and evaluation of ECD programs in societies affected by conflict. During its initial phase, the network is supporting the development of programs in Egypt, Mali, Kyrgyzstan, Tajikistan, Timor-Leste and Vietnam. There are also pilot programs being developed in Colombia, Israel and Palestine. The LINKS team hopes to explore whether ECD programs can not only play a key role in contributing to sustainable development, but that they can make a significant contribution to peacebuilding. Aligned with this, the LINKS Initiative also seeks to develop a measurement framework which can be used as a resource for governments, policy makers, researchers, and ECD service providers working in conflict-affected areas.

\section{Exemplars of the LINKS Initiative:}

The Mama Yeleen program in Mali (authored by Y. Togo). Mama Yeleen is an ECD parenting program developed by UNICEF. It is currently being piloted in five locations in Mali (Gao, Mopti, Ségou, Sikasso, and Timbuktu) as well as in other countries in Sub-Saharan Africa (UNICEF, 2019b). In Mali, experienced mothers are now being trained to implement the Mama Yeleen, which translates as "Model Mothers" or "Light Mothers" in Bambara, the national 
language of Mali. The overall goal of the program is to provide nurturing care and promote positive parenting practices within the communities, as well as to reduce levels of parental stress. In addition to the participating mothers, fathers are both direct and indirect participants in the program.

This program is urgently needed as Mali has a "very poor" FI of just 0.14 . Most of the modules of the Mama Yeleen program focus on providing support to expectant mothers and women with children aged 0 to 1,000 days. The Mama Yeleen program includes 15 key modules that, among other topics, include the importance of prenatal visits, the benefits of breastfeeding and adequate nutrition. Other modules include the importance of a parent interacting, stimulating and playing with her or his child over the course of her or his development, as well as the use of positive parenting techniques to discipline the child. Participating mothers are also actively encouraged to access Centers for Early Childhood Development to support their older children's cognitive and socio-emotional development. In addition, the Mama Yeleen program aims to build social cohesion within the community by establishing women's networks that can serve as platforms for mothers to reflect on their place within their local community and to be a source of support for one another. This child-based program is designed to reduce domestic violence in the home by promoting games and fun activities in which both parents and their child participate.

Traditionally in Mali, parents rarely say "I love you" to their child. While all parents love their children, their way of loving their children is typically focused on ensuring the child's safety by avoiding dangers as well as keeping them clean and feeding them. Historically, there were many things that women did that were not always in the best interests of themselves and their children. For example, some women hid their pregnancy, often even from their husbands at 
the start of their pregnancies. Many mothers (19.3\%) never went to community health centers, and $32.8 \%$ of them gave birth at home (INSTAT, 2019).

In the communities where Mama Yeleen is being piloted, several positive outcomes have been reported for participating children and their families, as well as in each community as a whole. Now, most expectant mothers are seeking prenatal care at their local health center and appreciate the importance of breastfeeding and good nutrition. One of the participating mothers who learned about the benefits of exclusive breastfeeding to children under six months of age said, "We do everything we can to make sure that our children are well fed and healthy." In addition, more mothers are using local produce and agricultural products to prepare nutritious foods for their children and families. Another mother reported, "This actually allowed us to reduce our expenses because when our child was sick, it cost us all our savings." Thanks to Mama Yeleen, many mothers have also gained a better understanding of their need to directly interact and play with their infants and toddlers. Likewise, some women in rural communities said that before the program, they would rarely see fathers playing with their children. The fathers would say that they were "too busy" to play with their children. Now, many more fathers are actively engaged in child rearing without using harsh psychological or physical discipline. In the past, the father and mother were almost never seen playing together with the child. Now, when the child cries, both the father and mother often try to console their child.

The Mama Yeleen program has been reported by participating families to have significantly reduced their level of harsh punishment toward their children. Now, parents are aware of the long-term negative consequences that harsh punishment can have on their children that can extend into adulthood, as well as impact how they will behave when they become parents. 
Mama Yeleen's impact regarding social cohesion has been impressive, according to the Local Development Service in the Ségou region where the program has been piloted. The program has provided an opportunity for mothers to get to know one another. For example, mothers are now organizing events in their community, such as cooking classes, where they can interconnect and give each other advice on how to find solutions to problems affecting their children and family. Some of the participants who were once shy have become very open. They can now spend the whole day at their neighbors' homes engaging in social events. Remarkably, the mothers work together to set up "tontines" to overcome financial difficulties, especially during social events such as weddings or baptisms. Each month, most of the mothers contribute between 100 and 500 francs for tontines and then they make a joint decision to give a tontine to cover the needs of one or more families. This continues in turn until each family has received it once and then they resume.

Despite the initial positive qualitative results of the program, Mama Yeleen faces many limitations and challenges that threaten its sustainability. Some of these limitations and challenges are related to its implementation and cost. UNICEF hopes that the Mali government will soon decide to provide programmatic and financial support for Mama Yeleen. However, in the current context, Mali's budget priorities are given primarily to ensure the safety of communities. Likewise, the ongoing COVID-19 pandemic has also placed the program in financial jeopardy. Also, the mothers who implement Mama Yeleen are volunteers who receive very little financial support. As a result, many of these volunteer mothers are tempted to leave the program at the first opportunity they have to engage in income-generating activities. Consequently, many program implementation sites frequently need to recruit, hire and train 
additional staff. This has the effect of delaying the implementation of the program as well as placing the program at risk for discontinuation.

Another major challenge for Mama Yeleen with respect to its impact is related to the continued involvement of fathers. In Malian society, the father is usually the decision-maker in the family (INSTAT, 2019). As a result, the father can decide that his wife should no longer participate in the program. Lastly, the program has yet to determine how best to build, or even measure, social cohesion across neighboring villages that have a history of being in conflict with one another.

\section{Increasing resilience of youth for peaceful and inclusive communities in Kyrgyzstan and} Tajikistan (authored by J. Kurbonov and N. Choibekov). Ongoing sporadic tensions among neighboring villages that lie on the border between Tajikistan and Kyrgyzstan have weakened intercommunity trust and caused an environment of uncertainty that has adversely affected children. For example, communities in the densely populated area of Ferghana Valley (Northern Tajikistan) were traditionally intertwined - sharing the same roads, electricity supply and water sources. Now, in the post-Soviet era, levels of tension and violence have increased due to limited access to land, roads and water (Tajikistan, 2011; Trilling, 2014). Intercommunity hostility has brought about a toxic environment, making it difficult for families to access social services needed to provide adequate nurturing care to their children. Indeed, many members of these communities have reported having an awareness of "invisible borders" between families of different ethnic backgrounds that keep themselves physically and socially distant from members of the "other" community. When interacting with members of another ethnic group, they are often cautious and suspicious. 
In part, because of the ongoing tensions in Kyrgyzstan and Tajikistan, a majority of children aged 3-5 years old are severely deprived of quality, early learning programs. Now, thanks to the UNICEF country offices in Tajikistan (UNICEF) (https://www.unicef.org/tajikistan/what-we-do), a number of low-cost programs are now in place to foster the health and the nutritional needs of young children. There are now more than 70 community-based Early Childhood Education (ECE) centers spread across the border of the two countries, where children from Tajik, Uzbek and Kyrgyz minorities have the opportunity to receive their first learning experiences as well as build positive and healthy peer relationships within and across their ethnic groups (Tajikistan, 2011). In addition, in Kyrgyzstan between 2015-2016, 17 community-based kindergartens designed to support social cohesion were opened with support of UNICEF and the Department of International Development in the United Kingdom (UNICEF report, 2016).

Remarkably, these "invisible borders" do not exist in the local ECE centers where young children play, eat, and sleep together. Although they do not speak the same language, they can easily understand one another. However, adverse events occurring within a community can compromise this sense of togetherness. For example, a teacher in a Tajik school on the border zone with the Lailak district of the Kyrgyz Republic said that, "When that incident happened (a violent interaction that took place in the Lailak region), Tajik and Kyrgyz families asked their children to stop playing with each other, and my 4-year-old grand-daughter asked me why she could not speak with the Kyrgyz children from the neighborhood, and this question made me think a lot about this issue".

Over the past four years, this program, in close cooperation with government officials and local education authorities, is providing support for a number of ECD services including: 1) 
increased access to ECD services for young children and families from ethnically and linguistically diverse backgrounds; 2) expansion of the curriculum for Tajikistan's Teachers Training Institute to include opportunities for multi-lingual education and peacebuilding elements; 3) promotion of social cohesion and peacebuilding through the formation of culturally and ethnically diverse parenting programs and child-friendly media materials; and 4) support of stakeholders from both Kyrgyzstan and Tajikistan to develop the skills needed for peaceful collaboration. It is hoped that the above-mentioned interventions will directly contribute to the creation of inclusive, tolerant and peaceful societies, when an increasing number of children and parents see diversity, interaction, and tolerance as enriching for their community.

With the support of the LINKS initiative, this project also seeks to develop culturally appropriate tools for monitoring and evaluating the impact of the program, both quantitatively and qualitatively. Alongside randomized controlled trials, plans are also in place to conduct qualitative research to better understand the attitudes and perceptions among children, their parents/caregivers and ECE teachers in relation to socio-ethnic and linguistic differences that exist within their communities. Data from this research will generate evidence to influence existing attitudes, expectations and practices through a set of targeted programmatic interventions at individual, family, and community levels.

Many of the participants are quite positive about the program and its impact. For example, the mother of two young sons from the Jabbor Rasulov district of Tajikistan, where most of the residents are from the Uzbek minority, stated, "My son Ahliddin was in the ECE program during the 2018-2019 academic year, and he successfully started his primary school at the local school, and he now speaks more Tajik with me, though we are Uzbek. He has improved his communication skills". 
Another project, "Social Cohesion in Early Childhood Development," is also underway. This project seeks to document the impact of an animated cartoon series entitled the "Magic Journey" (Solodunova, 2007). The Magic Journey began in November 2006 and is set to run every evening as part of a one-year project by the National Kyrgyz Tele/Radio Corporation, with support from UNICEF, the Aga Khan Foundation and the Early Childhood Development Programme. This broadcast cartoon reaches the most remote regions of Kyrgyzstan. Every episode invites children and their parents to send in their story ideas for future episodes. In this way, children have become regular contributors and are actively creating their own magic journey.

The Integrated Early Childhood Development Program in Vietnam - Changing the Lives of Young Children and Their Families (authored by H.T.T. Phan). Despite enormous improvements in the care and education of young children in Vietnam, made during the last few decades, young children under 8 years of age remain exposed to multiple deprivations in health, nutrition, education and protection, especially in the remote rural northern mountainous and central highland areas of Vietnam. In this context, an Integrated Early Childhood Development (IECD) program was launched in 2017 to improve the quality of and access to ECD services for young children and their families (UNICEF Vietnam, 2018). The IECD is a comprehensive life cycle-based approach involving policies, service provision and intervention programs for children from conception to 8 years of age, and for their parents/caregivers and the communities in which they live. The IECD program offers multifaceted interventions in "nurturing care" while emphasizing the promotion of holistic positive parenting and children's social-emotional development. The interventions are delivered through health centers, schools, and IECD 
parenting clubs in each village, or commune. Parents and caregivers gather regularly at the IECD clubs to learn about childcare and practice parenting skills under the guidance of facilitators.

The overall aim of the IECD program is to reduce maternal and neonatal deaths, eliminate stunting and promote a clean environment, good hygiene, early stimulation, early learning, and holistic parenting. Furthermore, the IECD program hopes to strengthen social cohesion within the project communities through its activities (UNICEF Vietnam, 2018). The activities include efforts to build trust and social cohesion by initiating programs that promote community engagement, mutual support, and solidarity between families, children and caregivers from different ethnic groups, as well as between families and ECD providers and government officials. Improving social cohesion will clearly help to support the development of young children while building a foundation for sustainable peace for the whole society.

Since 2017, a pilot implementation of the IECD program has been carried out in 27 of the most disadvantaged communities in nine districts of the three poorest provinces in Vietnam. Building social cohesion in these three provinces is a challenge, given the high degree of ethnic diversity. Each community has its own language and customs and their citizens tend to only interact within their own ethnic group (UNICEF Vietnam, 2018). The pilot implementation of the IECD program was completed in early 2020 involving approximately 35,000 children aged 0-8 and 25,000 parents and caregivers (UNICEF Vietnam, 2020a; UNICEF Vietnam, 2020b). Endline assessments for the program's impact on the quality of and access to ECD services are currently underway. The impact of the IECD program on social cohesion is being evaluated by a team of three national researchers involved in the LINKS network who are implementing a mixed methods approach in intervention and control groups that involve questionnaires, FGDs, and in-depth interviews with ECD service providers and parents. 
To date, the research team found that the IECD program has brought about positive changes in parents' and caregivers' beliefs and attitudes toward, and practices of child upbringing. For example, an illiterate 45-year-old mother of a one-year-old boy from her second marriage said: "I feed and care for him [her youngest son] totally differently from the older ones [two adult children from her first marriage]. That's thanks to the workshops [at IECD parenting club]. Before we didn't know how to feed and care for our babies in a good way". Many of the parents report that they now believe that physical punishment can harm their children and that their interactions with their young children are much more positive.

Based on these interviews, it also appears that newly acquired knowledge in child upbringing and participation in different IECD related activities has increased the level of social cohesion within participating communities. Interviewed parents said that they now ask for help not only about parenting but also about other issues of life and work. Many of the parents also indicated that they now have greater trust in the local authorities that support ECD services.

The delivery of these programs to ethnic minority children and families living in remote areas of Vietnam is a high priority. But there are still several obstacles to overcome. These include geographically distant locations with long travel times, as well as language barriers, and cultural practices, norms and values that are unique to each ethnic group. In addition, recruiting and retaining qualified staff in each community has been a challenge given the limited funds currently available.

Next Steps. As these programs come of age, they need to bring closer together the agendas on environmental sustainability and child development, given the linkages between biophilia in early childhood and the role of human action in preserving the planet. In doing so, ECD programs provide a pathway towards climate resilience and adaptation capacity. The biophilic 
tendency, which needs to be nurtured during early childhood, allows young children to develop empathy for the animate world, flora and fauna, as they do with the human world, thereby cultivating human relationships with nature and conservation.

Strategy 3: Mentoring the next generation of scholars in child development - The Edward Zigler Center in Child Development and Social policy - and the Child Study Center, Yale University. A lasting legacy of Edward Zigler is the generation of scholars he inspired and mentored. Under his leadership, the Edward Zigler Center (EZC) opened a global arm that fostered partnerships among faculty and scholars from around the world. For example in 2015, the EZC partnered with researchers from Harvard University and Aga Khan Universities to develop, implement, and scale-up one of the few robustly-evaluated youth-led ECD programs in a LMIC, the Youth Leaders for Early Childhood Assuring Children are Prepared for School (LEAPS) program (Ponguta, Rasheed, Reyes, \& Yousafzai, 2018b; Yousafzai, 2019). LEAPS is a set of cross-generational programs that aim to train, mentor and empower youth to promote the demand for quality ECD programming in their communities. Indeed, LEAPS is an evidencebased program that is contextually-aligned, directly providing programmatic opportunities for the youth that are closely aligned with a number of the UN's 2030 SDGs (Clark et al., 2020).

Youth-led ECD programs like LEAPS address ECD workforce gaps, which is a critical barrier to accessible services, while meeting youth development, leadership and employment needs. In addition, from an individual developmental trajectory perspective, executive function skill proficiency develops more acutely during early childhood and youth years compared to later periods of development (Daelmans et al., 2017). As a result, the LEAPS program offers a unique opportunity to promote a developmental period known to be critical to multiple learning and behavioral outcomes throughout the life course. In addition, macroeconomic evidence shows that 
investing in early learning and youth development yields greater cost savings than investments later in life. Below, we present two exemplars of the LEAPS program in Pakistan and Colombia.

\section{Exemplars of the LEAPS initiative:}

\section{Youth Leaders for Early Childhood Assuring Children are Prepared for School -}

Pakistan (authored by L.A. Ponguta). In Pakistan, LEAPS has utilized a cross-generational strategy to support learning and the development of young children (3.5 to 6.5 years of age) and female youth (18 to 24 years of age) (Ponguta et al., 2020; Ponguta et al., 2018b). Preschools run by the Community Youth Leaders (CYLs) implement LEAPS in two groups per day. At the time of enrolment, the first group includes children 3.5 to 4.5 years of age and the second group includes children 4.6 to 5.5 years of age. Each group completes a 3-hour session for 5 days per week (Ponguta et al., 2020; Yousafzai et al., 2018).

Attention to quality is a central pillar of the LEAPS program. To this end, the proposed CLY-to-child ratio follows the national standards in Pakistan. During the pilot, candidates were selected to participate in the basic 4-week training after a 1-day workshop to evaluate skills, creativity, problem solving, planning and leadership skills. Successful candidates enrolled in a 6month vocational training where they are paired with an experienced mentor. The pedagogical approach is holistic, evidence-based and culturally relevant. The program also promotes communities of practice to encourage peer-to-peer learning. The program has a community and family-engagement strategy, adaptable to different local contexts, to promote demand and wider stakeholder participation.

A recently-completed RCT (ClinicalTrials.gov \# NCT02645162) (Khizar, 2016) of the LEAPS program ( $\mathrm{n}=340$ children) demonstrated that children who participated in the program scored higher on key developmental indicators with an average effect size of 0.3 ranging from 
0.1 on the motor skills sub-test to 0.6 on the socioemotional skills sub-test (Yousafzai et al., 2018). CYLs scored higher in executive function tests after participating in the program and reported increased sense of empowerment and professional growth (Yousafzai et al., 2018). The program is currently being taken to scale in Pakistan, where adjustments to implementation and an assessment of the system's uptake are being tested to increase access while sustaining the program's impact.

\section{Youth Leaders for Early Childhood Assuring Children are Prepared for School -}

Colombia (authored by L. A. Ponguta). Given the success of the LEAPS initiative in Pakistan, work is also now underway to explore the feasibility of implementing LEAPS in target municipalities in Colombia. Working with local leaders and academic partners, the LEAPS implementing team is currently in the process of rolling out a study to assess: 1) the governmental support and assessment of governance and institutional arrangements for program sustainability and scale-up; 2) the attributes of youth buy-in for program participation and assessment of the benefits of the program for youth professional development in the Colombian context; 3 ) the nature of community and family perceptions and level of acceptability of youthled programming for early childhood; and 4) the processes to establish academic partnerships and mentoring for sustained program implementation and evaluation. The initial plan is to conduct a qualitative study to characterize the above areas, as a first step to determine key attributes of the program's adaptation. The data will then be utilized as a key set of preliminary

findings to rollout a culturally adapted and contextualized program in Colombia, scheduled to be piloted in 2020 .

\section{Closing Remarks}


This review article has been co-authored by three generations of scholars, each of whom has been either directly mentored by Edward Zigler or by one of his mentees. It was inspired by his determination to improve and sustain ECD programs through rigorous research and effective advocacy. By linking ongoing ECD efforts across the globe with Edward Zigler's vision and determination, we have sought to demonstrate both the impact of his work and the reality that much more needs to be done, in the United States and beyond. Indeed, the magnitude of what needs to be done for the next generation is truly daunting (Clark et al., 2020).

Given the importance of this topic, we as partners, must continue to expand the evidence that will engage government officials and policy-makers around the globe to invest in ECD and parenting services, using a multi-sector approach. Governments are asking for national level evidence and data that is applicable to their implementation contexts. We need to continue to support young scholars to generate this much-needed evidence.

At present, we urgently need to join with UNICEF and our other global partners to find ways to limit the negative impact of the ongoing COVID-19 pandemic. Children are, in many ways, the hidden victims of this pandemic. Some of the ECD programs mentioned above are being scaled-back or discontinued. School closures across the world are having a negative impact on their cognitive and socio-emotional development, their nutritional status, and their access to basic health services. For children on the move or living through conflicts, the long-term consequences will likely be even more problematic. We also need to generate evidence that links ECD with Climate Action, because the harmful effects of climate change and pollution are being disproportionately borne by young children under 5 years of age. The next generation of ECD evidence needs to address climate change, just as previous generations have addressed the harmful impact of poverty and other societal challenges (Clark et al., 2020). 
In keeping with Edward Zigler's focus on continuous program improvement, we also need to initiate and sustain an ongoing dialogue with the families that are being served. A crucial component of improving quality is to take the beneficiary perspective into consideration; indeed, it is an ethical imperative (LEGO Foundation \& UNICEF, 2019; Ponguta et al., 2018a). Taking into consideration the beneficiary perspective and the demand side of services is a very important component to improving quality. Thus far, ECD programs design has focused on the supply side of the program. Required for greater effectiveness and scale-up are flexible programs that take into consideration the needs and cultural dimensions of the beneficiaries. Also, we must use cutting edge technology to facilitate data collection and analysis in order to improve quality of ECD services. In this regard, our colleagues at the Harvard Humanitarian Initiative in collaboration with the LINKS Initiative have introduced the KoBoToolbox, which is designed to use the latest information technology to collect and analyze data using culturally appropriate measurement tools (https://www.kobotoolbox.org/). KoBoToolbox is a freely available resource to researchers across the globe working in fragile and challenging settings. Given the closing of many ECD programs due to the COVID-19 pandemic, there is clear need to embrace to global telehealth opportunities provided by the KoBoToolbox.

The Edward Zigler Center in Child Development and Social Policy has played a key role in propelling ECD policy development and advocacy nationally and internationally. Guided by Zigler's approach to policy analysis and advocacy, a new generation of translational and applied research has addressed the need to assess the equitability and quality of ECD services in LMICs. These include systems-level analyses of ECD governance and finance as well as some of the first assessments of ECD service quality at scale in resource-constrained settings (Britto et al., 2014; Ponguta et al., 2019b; Ponguta et al., 2019c). 
We also need to find a way to support the next generation of youth to become leaders in this field and to support them as partners and leaders in decision-making and in peacebuilding processes, as stipulated in the resolution on Youth, Peace and Security adopted by the UN Security Council in 2015 (UNSCR 2250). For far too long, young people have been sidelined. The recent WHO-UNICEF-Lancet Commission identified a number of barriers to their engagement and this must change (Clark et al., 2020). The voices of the children and the youth need to be heard and we need to promote their full and effective participation in efforts of ECDAN and the ECPC (Gatera \& Pavarini, 2020).

Finally, the global community needs to invest in the careers and wellbeing of the local practitioners who are implementing these ECD and parenting programs (Clark et al., 2020; Leckman, Donaldson, Affolter, \& Ponguta, 2019; Ponguta et al., 2018b). Third, the global community needs to invest in the careers and wellbeing of the practitioners within the community who are implementing these ECD and parenting programs (Ponguta et al., 2018a). A lasting legacy of Edward Zigler is that he invested in people-his staff, his mentees, his students, and his junior scholars. This is an intergenerational investment that has had a multiplier effect not only on the research and policy expansion, but on expanding the agenda to give each child the best possible start to life. 


\section{References}

AÇEV—Anne Çocuk Eğitim Vakfi. (2008). Building a generation of reconciliation: The role of early childhood in peace building. Istanbul, Turkey: Mother-Child Education Foundation Publications.

AÇEV—Anne Çocuk Eğitim Vakfi (Mother Child Education Foundation). (2012). Building a generation of reconciliation: The role of early childhood development in peace building. Istanbul, Turkey: Mother-Child Education Foundation Publications.

Al Eissa, M., \& Almuneef, M. (2010). Child abuse and neglect in Saudi Arabia: Journey of recognition to implementation of national prevention strategies. Child Abuse \& Neglect, 34(1), 28-33. doi: 10.1016/j.chiabu.2009.08.011

Alzahrani, T. A., Abaalkhail, B. A., \& Ramadan, I. K. (2016). Prevalence of intimate partner violence and its associated risk factors among Saudi female patients attending the primary healthcare centers in Western Saudi Arabia. Saudi Medical Journal, 37(1), 9699. doi: $10.15537 / \mathrm{smj} .2016 .1 .13135$

Bekman, S., \& Koçak, A. A. (2011). Beş Ülkeden Anneler Anlatıyor I: Anne-Çocuk Eğitim Programı Kimler İçin ve Neden Etkili? Eğitim ve Bilim, 36(160).

Black, M. M., Walker, S. P., Fernald, L. C. H., Andersen, C. T., DiGirolamo, A. M., Lu, C., .. . Grantham-McGregor, S. (2017). Early childhood development coming of age: Science through the life course. Lancet, 389(10064), 77-90. doi: 10.1016/s0140-6736(16)31389-7

Britto, P., Gordon, I., Hodges, W., Sunar, D., Kağıtçıbaşı, C., \& Leckman, J. (2014). Ecology of peace. In J. F. Leckman, C. Panter-Brick \& R. Salah (Eds.), Pathways to peace: The transformative power of children and families, (pp. 27-39). Vol. 15. MIT Press. 
Britto, P. R., \& Gilliam, W. S. (2008). Crossing borders with Head Start: Commonalities and differences between Head Start and early childhood programs in developing countries. Infants \& Young Children, 21(1), 82-91. doi: 10.1097/01.IYC.0000306375.25167.3d

Britto, P. R., Lye, S. J., Proulx, K., Yousafzai, A. K., Matthews, S. G., Vaivada, T., .. . Bhutta, Z. A. (2017). Nurturing care: Promoting early childhood development. Lancet, 389(10064), 91-102. doi: 10.1016/s0140-6736(16)31390-3

Britto, P. R., Singh, M., Dua, T., Kaur, R., \& Yousafzai, A. K. (2018). What implementation evidence matters: Scaling-up nurturing interventions that promote early childhood development. Annuals of the New York Academy of Sciences, 1419(1), 5-16. doi: $10.1111 /$ nyas. 13720

Cicchetti, D., \& Sroufe, L. A. (2000). The past as prologue to the future: The times, they've been a-changin'. Development \& Psychopathology, 12(3), 255-264. doi: $10.1017 / \mathrm{s} 0954579400003011$

Clark, H., Coll-Seck, A. M., Banerjee, A., Peterson, S., Dalglish, S. L., Ameratunga, S., . . Costello, A. (2020). A future for the world's children? A WHO-UNICEF-Lancet Commission. Lancet, 395(10224), 605-658. doi: 10.1016/s0140-6736(19)32540-1

Connolly, P., Hayden, J., \& Levin, D. (2007). From Conflict to Peace Building: The power of early childhood initiatives. Paper presented at the Lessons from around the World. Redmond, WA: World Forum Foundation.[3, 17-19].

Connolly, P., Miller, S., \& Eakin, A. (2010). A cluster randomised trial evaluation of the media initiative for children: Respecting difference programme. Belfast: Centre for Effective Education, Queen's University Belfast. 
Daelmans, B., Darmstadt, G. L., Lombardi, J., Black, M. M., Britto, P. R., Lye, S., .. . Richter, L. M. (2017). Early childhood development: The foundation of sustainable development. Lancet, 389(10064), 9-11. doi: 10.1016/s0140-6736(16)31659-2

Gatera, G., \& Pavarini, G. (2020). The voices of children in the global health debate. The Lancet, 395(10224), 541-542. doi: 10.1016/S0140-6736(20)30364-0

Graham, G., Kirollos, M., Knag Fylkesnes, G., Salarkia K., \& Wong N. (2019). Stop the War on Children: Protecting children in 21st century conflict. Save the Children International. Germany: GmbH \& Co.KG.

Greenberg, P. (2004). Three core concepts of the war on poverty: Their origins and significance in Head Start. The Head Start Debates, 61-84.

Heckman, J. J., Moon, S. H., Pinto, R., Savelyev, P. A., \& Yavitz, A. (2010). The rate of return to the HighScope Perry Preschool Program. Journal of Public Economics, 94(1-2), 114128. doi: 10.1016/j.jpubeco.2009.11.001

Heckman, J. J., \& Raut, L. K. (2016). Intergenerational long-term effects of preschool-structural estimates from a discrete dynamic programming model. Journal of econometrics, 191(1), 164-175. doi: 10.1016/j.jeconom.2015.10.001

Hein, S., Bick, J., Issa, G., Aoude, L., Maalouf, C., Awar, A., . . Ponguta, L. A. (2020). Maternal perceptions of father involvement among refugee and disadvantaged families in Beirut, Lebanon. PloS one, 15(3), e0229670-e0229670. doi:

10.1371/journal.pone.0229670

Hillis, S. D., Mercy, J. A., \& Saul, J. R. (2017). The enduring impact of violence against children. Psychology, Health \& Medicine, 22(4), 393-405. doi:

$10.1080 / 13548506.2016 .1153679$ 
INSTAT. (2019). Sixième Enquête Démographique et de Santé au Mali 2018. Retrieved from Bamako, Mali: www.DHSprogram.com

Kağıtçıbaşı, Ç., Sunar, D., Bekman, S., Baydar, N., \& Cemalcilar, Z. (2009). Continuing effects of early enrichment in adult life: The Turkish Early Enrichment Project 22 years later. Journal of Applied Developmental Psychology, 30(6), 764-779.

10.1016/j.appdev.2009.05.003

Kağıtçıbaşı, Ç., Sunar, D., \& Bekman, S. (2001). Long-term effects of early intervention. Journal of Applied Developmental Psychology, 22, 333-361. doi: 10.1016/S01933973(01)00071-5

Khizar, A. (2016). Youth Leaders for Early Childhood Assuring Children Are Prepared for School (LEAPS). Retrieved from https://clinicaltrials.gov/ct2/show/NCT02645162

Lakkis, N.A., Osman, M.H., Aoude, L.C., Maalouf, C.J, Issa, H. G., \& Issa, G.M. (2020). A pilot intervention to ptomote positive parenting in refugees from Syria in Lebanon and Jordan. Frontiers in Psychiatry, 11(257). doi: 10.3389/fpsyt.2020.00257.

Leckman, J. F., Donaldson, C. K., Affolter, F. W., \& Ponguta, L. A. (2019). Pathways to Wellbeing and a More Peaceful and Sustainable World: The Transformative Power of Children and Families. Japanese Journal of Child and Adolescent Psychiatry, 60(3), 278298. doi: $10.20615 /$ jscap.60.3_278

Leckman, J. F., Panter-Brick, C., \& Salah, R. (2014). Pathways to peace: The transformative power of children and families (Vol. 15): MIT Press, Cambridge, MA, USA.

LEGO Foundation \& UNICEF (2019). Toward the Next Generation of Early Childhood Development Parenting Interventions. Retrieved from: https://repository.najah.edu/bitstream/handle/20.500.11888/14758/Toward_the_Next_Ge 
neration_of_Early_Childhood_Development_Parenting_Interventions_Knowns_Unknow ns\%2C_and_What_Should_be_Known.pdf? sequence=1\&isAllowed $=\mathrm{y}$

Ponguta, L. A., Aggio, C., Moore, K., Hartwig, E., Jang, B., Markovic, J., . . Grover, D. (2019c). Exploratory analysis of decentralized governance and its implications for the equity of early childhood education services in four countries of Europe and Central Asia. Early Years, 39(3), 326-342. doi: 10.1080/09575146.2019.1634009

Ponguta, L. A., Donaldson, C., Affolter, F., Connolly, P., Dunne, L., Miller, S., . . Leckman, J. (2018a). Early childhood development programs, peacebuilding, and the sustainable development goals: Opportunities for interdisciplinary research and multisectoral partnerships Developmental Science and Sustainable Development Goals for Children and Youth (pp. 77-95): Springer.

Ponguta, L. A., Issa, G., Aoudeh, L., Maalouf, C., Hein, S. D., Zonderman, A. L., . . Awar, A. (2020). Effects of the Mother-Child Education Program on parenting stress and disciplinary practices among refugee and other marginalized communities in Lebanon: A pilot randomized controlled trial. Journal of the American Academy of Child \& Adolescent Psychiatry. 020 Jan 31. pii: S0890-8567(20)30066-6. doi: 10.1016/j.jaac.2019.12.010 . [Epub ahead of print]

Ponguta, L. A., Issa, G., Aoudeh, L., Maalouf, C., Nourallah, S., Khoshnood, K., . . Salah, R. (2019a). Implementation evaluation of the Mother-Child Education Program among refugee and other vulnerable communities in Lebanon. New Directions for Child and Adolescent Development, 2019, 167, 91-116. doi: 10.1002/cad.20314

Ponguta, L. A., Maldonado-Carreño, C., Kagan, S. L., Yoshikawa, H., Nieto, A. M., Aragón, C. A., ... Escallon, E. (2019b). Adaptation and application of the measuring early learning 
quality and outcomes (MELQO) framework to early childhood education settings in Colombia. Zeitschrift für Psychologie, 227,105-112. doi: 10.1027/2151-2604/a000361

Ponguta, L. A., Rasheed, M. A., Reyes, C. R., \& Yousafzai, A. K. (2018b). A conceptual model for youth-led programs as a promising approach to early childhood care and education. New Directions for Child and Adolescent Development, 2018, 159, 71-89. 2. doi: $10.1002 /$ cad.20233

Rodrigues, N. C. P., O'Dwyer, G., Andrade, M. K. N., Flynn, M. B., Monteiro, D. L. M., \& Lino, V. T. S. (2017). The increase in domestic violence in Brazil from 2009-2014. Cien Saude Colet, 22(9), 2873-2880. doi: 10.1590/1413-81232017229.09902016

Shonkoff, J. P., \& Garner, A. S. (2012). The lifelong effects of early childhood adversity and toxic stress. Pediatrics, 129(1), e232-246. doi: 10.1542/peds.2011-2663

Solodunova, G. (2007). Cartoon takes Kyrgyz children on a 'Magic Journey' and teaches life lessons. Cartoon takes Kyrgyz children on a 'Magic Journey' and teaches life lessons. Retrieved from Retrieved from https://www.unicef.org/earlychildhood/kyrgyzstan_37948.html

Sunar, D., Kagitcibasi, C., Leckman, J., Britto, P., Panter-Brick, C., Pruett, K., . . Yazgan, Y. (2013). Is early childhood relevant to peacebuilding? Journal of Peacebuilding \& Development, 8(3), 81-85. doi: 10.1080/15423166.2013.865493

Tajikistan, U. (2011). Potential for peace and threats of conflict: Development analysis of crossborder communities in Isfara District of the Republic of Tajikistan (Vorukh, Chorkhuh, Surkh, Shurab) and Batken District of the Kyrgyz Republic (Ak-Sai, Ak-Tatyr, and Samarkandek). Retrieved from 
https://www.yumpu.com/en/document/view/31527916/potential-for-peace-and-threatsof-conflict-undp-in-tajikistan

Trilling, D. (2014). Kyrgyzstan-Tajikistan: What's next after border shootout? EuasiaNet.org, 13 January 2014, (www.eurasianet.org/node/67934).

United Nations. (2020). About the Sustainable Development Goals. Retrieved from https://www.un.org/sustainabledevelopment/sustainable-development-goals/ UNESCO. (2006). Strong Foundations: Early Childhood Care and Education-EFA Global Monitoring Report 2007. (EFA Global Monitoring Report, 2nd rev. ed.). Paris: France United Nations Children's Fund (UNICEF). (2019a). 29 million babies born into conflict in 2018 [Press release]. Retrieved from https://www.unicef.org/press-releases/29-million-babiesborn-conflict-2018

United Nations Children's Fund (UNICEF). (2019b). UNICEF Model Mothers lead the way for moms and their babies. Retrieved from https://www.unicefusa.org/stories/unicef-modelmothers-lead-way-moms-and-their-babies/35959

United Nations Children's Fund (UNICEF) Tajikistan (2016). UNICEF Annual Report 2016 Tajikistan. Retrieved from https://www.unicef.org/about/annualreport/files/Tajikistan_2016_COAR.pdf United Nations Children's Fund (UNICEF) Vietnam. (2018). The Integrated Early Childhood Development Programme 2017-2021 of UNICEF. Retrieved from https://www.unicef.org/vietnam/media/3766/file/Baseline\%20Assessment\%20Report.pdf United Nations Children's Fund (UNICEF) Vietnam. (2020a). Integrated Early Childhood Development. Retrieved from: https:/www.unicef.org/vietnam/integrated-earlychildhood-development 
United Nations Children's Fund (UNICEF) Vietnam. (2020b). Early childhood development. Retrieved from https://www.unicef.org/vietnam/integrated-early-childhood-development United Nations General Assembly. (1999). Declaration and Program of Action on a Culture of Peace (UN Resolution A/RES/53/243, adopted in September 1999).

United Nations General Assembly. (2015). Transforming our world: The 2030 Agenda for Sustainable Development. Retrieved from https://sustainabledevelopment.un.org/post2015/transformingourworld

Yousafzai, A., et al. (2019). LEAPS: A strategy to benefit young children and youth. Vol 2019, 102-105. Retrieved from https://earlychildhoodmatters.online/2019/leaps-a-strategy-tobenefit-young-children-and-youth/

Yousafzai, A. K., Rasheed, M. A., Rizvi, A., Shaheen, F., Ponguta, L. A., \& Reyes, C. R. (2018). Effectiveness of a youth-led early childhood care and education programme in rural Pakistan: A cluster-randomised controlled trial. PloS One, 13(12) e0208335. doi: 10.1371/journal.pone.0208335

Zigler, E., \& Anderson, K. (1979). An idea whose time had come: The intellectual and political climate for Head Start. In E. Zigler \& J. Valentine (Eds.), Project Head Start: A legacy of the war on poverty (pp. 3-19). New York: Free Press.

Zigler, E. F., \& Hall, N. W. (2000). Child development and social policy: Theory and applications. Boston: McGraw-Hill.

Zigler, E., \& Styfco, S. J. (2002). A life lived at the crossroads of knowledge and children's policy. New Directions for Child and Adolescent Development, 98, 5-15. doi: 10.1002/cd.54 